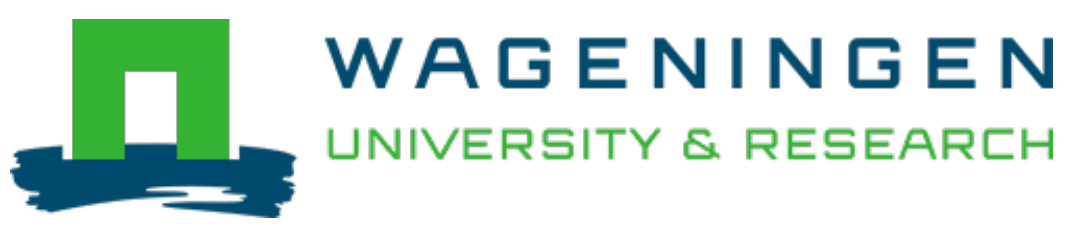

\title{
Complex microbiota of a Chinese "Fen" liquor fermentation starter (Fen-Daqu), revealed by culture-dependent and culture-independent methods
}

\author{
Food Microbiology \\ Zheng, X.; Zheng, Y.; Han, B.; Zwietering, M.H.; Samson, R.A. et al \\ https://doi.org/10.1016/j.fm.2012.03.008
}

This publication is made publicly available in the institutional repository of Wageningen University and Research, under the terms of article $25 \mathrm{fa}$ of the Dutch Copyright Act, also known as the Amendment Taverne. This has been done with explicit consent by the author.

Article 25 fa states that the author of a short scientific work funded either wholly or partially by Dutch public funds is entitled to make that work publicly available for no consideration following a reasonable period of time after the work was first published, provided that clear reference is made to the source of the first publication of the work.

This publication is distributed under The Association of Universities in the Netherlands (VSNU) 'Article $25 \mathrm{fa}$ implementation' project. In this project research outputs of researchers employed by Dutch Universities that comply with the legal requirements of Article $25 \mathrm{fa}$ of the Dutch Copyright Act are distributed online and free of cost or other barriers in institutional repositories. Research outputs are distributed six months after their first online publication in the original published version and with proper attribution to the source of the original publication.

You are permitted to download and use the publication for personal purposes. All rights remain with the author(s) and / or copyright owner(s) of this work. Any use of the publication or parts of it other than authorised under article $25 \mathrm{fa}$ of the Dutch Copyright act is prohibited. Wageningen University \& Research and the author(s) of this publication shall not be held responsible or liable for any damages resulting from your (re)use of this publication.

For questions regarding the public availability of this publication please contact openscience.library@wur.nl 


\title{
Complex microbiota of a Chinese "Fen" liquor fermentation starter (Fen-Daqu), revealed by culture-dependent and culture-independent methods
}

\author{
Xiao-Wei Zheng ${ }^{\mathrm{a}, \mathrm{b}}$, Zheng Yan ${ }^{\mathrm{b}}$, Bei-Zhong Han ${ }^{\mathrm{b}}$, Marcel H. Zwietering ${ }^{\mathrm{a}}$, Robert A. Samson ${ }^{\mathrm{c}}$, \\ Teun Boekhout ${ }^{c}$, M.J. Robert Nout ${ }^{\mathrm{a}, *}$ \\ a Laboratory of Food Microbiology, Wageningen University, P.O. Box 8129, 6700 EV Wageningen, The Netherlands \\ ${ }^{\mathrm{b}}$ College of Food Science and Nutritional Engineering, China Agricultural University, Beijing 100083, People's Republic of China \\ ${ }^{\mathrm{C}}$ CBS Fungal Biodiversity Centre, Royal Netherlands Academy of Arts and Sciences (KNAW), Uppsalalaan 8, 3584 CT Utrecht, The Netherlands
}

\section{A R T I C L E I N F O}

\section{Article history:}

Received 27 November 2011

Received in revised form

4 February 2012

Accepted 15 March 2012

Available online 23 March 2012

\section{Keywords:}

Daqu

Amylolytic starter

Microbial diversity

DGGE

Fungi

\begin{abstract}
A B S T R A C T
Daqu is a traditional fermentation starter that is used for Chinese liquor production. Although partly mechanized, its manufacturing process has remained traditional. We investigated the microbial diversity of Fen-Daqu, a starter for light-flavour liquor, using combined culture-dependent and cultureindependent approaches (PCR-DGGE). A total of 190 microbial strains, comprising 109 bacteria and 81 yeasts and moulds, were isolated and identified on the basis of the sequences of their 16S rDNA (bacteria) and 26S rDNA and ITS regions (fungi). DGGE of DNA extracted from Daqu was used to complement the culture-dependent method in order to include non-culturable microbes. Both approaches revealed that Bacillus licheniformis was an abundant bacterial species, and Saccharomycopsis fibuligera, Wickerhamomyces anomalus, and Pichia kudriavzevii were the most common yeasts encountered in Fen-Daqu. Six genera of moulds (Absidia, Aspergillus, Mucor, Rhizopus, Rhizomucor and Penicillium) were found. The potential function of these microorganisms in starters for alcoholic fermentation is discussed. In general the culture-based findings overlapped with those obtained by DGGE by a large extent. However, Weissella cibaria, Weissella confusa, Staphylococcus saprophyticus, Enterobacter aerogenes, Lactobacillus sanfranciscensis, Lactobacillus lactis, and Bacillus megaterium were only revealed by DGGE.
\end{abstract}

(ㄷ) 2012 Elsevier Ltd. All rights reserved.

\section{Introduction}

Chinese liquor is one of the world's oldest distilled alcoholic beverages, and plays an important role in Chinese culture and people's daily life. The total annual production of Chinese liquor was estimated at approximately 5 million metric tons per year (Anonymous, 2008). The popularity of Chinese liquor is in part due to the diversity of flavours. Chinese liquor flavours can be distinguished as strong-flavour [Nongxiang in Chinese] (Zhang et al., 2011a), light-flavour [Qingxiang in Chinese] and sauce-flavour [Jiangxiang in Chinese] (Shen, 2001; Wu et al., 2009; Zhang et al., 2011b). The liquor is made from cereals, mainly sorghum, by fermentation, distillation and maturation. Mixed culture starters (Fan et al., 2007), which are locally called "Daqu", are used as inoculum for the solid-state fermentation, as shown in Fig. 1. The cooked cereals are inoculated by mixing with approximately $9-10 \%$

\footnotetext{
* Corresponding author. Tel.: +31 317 482834; fax: +31 317484978.

E-mail address: rob.nout@wur.nl (M.J. Robert Nout).
}

powdered Daqu and this mixture is fermented in sealed jars for 21-28 days at $10-16{ }^{\circ} \mathrm{C}$. Daqu is an important saccharifying and fermenting agent for the production of Chinese liquor and traditional vinegar, and has a significant impact on the flavour of the final product (Shen, 2001; Zheng et al., 2011).

Daqu itself is also made by fermentation, which takes about one month. This is followed by a storage period of 6 months for maturation. The manufacture of Daqu by traditional uncontrolled solid-state fermentation techniques results in products with inconsistent quality; this causes large losses of unsuccessful products which go to waste as animal feed (Shen et al., 2005). Therefore standardization of the Daqu production process is an important objective for Chinese liquor producers. So-far, this has resulted in the application of modernized machinery, but little attention has been given so-far to the functional composition, i.e. the microbiota of Daqu, in view of controlling its fermentation.

Fen-Daqu is a light-flavour Daqu from Shanxi province, which is made from barley and pea, and contains around 50\% of starch (Zheng et al., 2011). "Fen-type" liquor has a flavour that is described as pure and sweet, with a refreshing aftertaste (Xiong, 2005). 


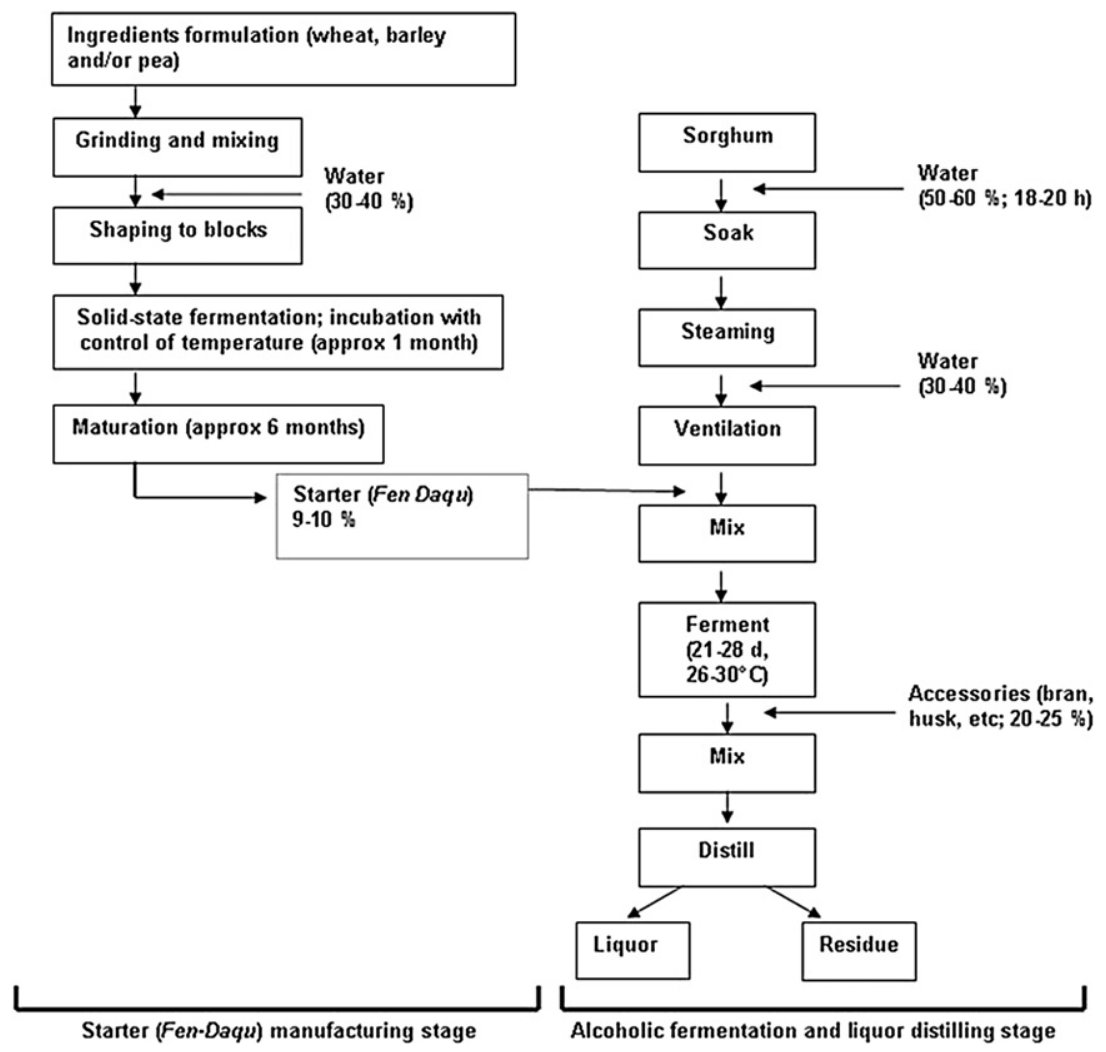

Fig. 1. Process diagram for the production of Fen-Daqu and its role in the production process of Chinese liquor.

During the production of Daqu by solid-state fermentation, the temperature in the Daqu blocks may increase up to $60^{\circ} \mathrm{C}$ as a result of metabolic heat. In Fen-Daqu production, care is taken to restrict maximum temperatures to $<50{ }^{\circ} \mathrm{C}$ by ventilation. Most microorganisms are expected to grow and survive these temperatures, and, therefore, Fen-Daqu is expected to contain a diverse microbial community.

Traditional microbiological methods such as enumeration using different general and selective media, can provide (i) quantitative data on the occurrence of different groups of microorganisms and (ii) isolated pure cultures for experimental fermentations. However, this classical culture-dependent approach only reveals the culturable microbes. Therefore, molecular microbiological methods such as analysis of direct DNA extracts by PCR-T/DGGE, pyrosequencing, sequencing of clone libraries, etc. are useful additions to realize rapid and high throughput microbial communities analysis (Aquilanti et al., 2007; Camu et al., 2007; Iacumin et al., 2009; Papalexandratou et al., 2011; Thanh et al., 2008). In this study we report an investigation of the microbial community in Fen-Daqu using combined culture-dependent and -independent approaches.

\section{Materials and methods}

\subsection{Sample collection and storage of Daqu}

Fen-Daqu was obtained from Shanxi Xinghuacun Fenjiu Group Company, the largest producer of light-flavour liquor. The dimensions of Daqu blocks are approximately $27 \times 16 \times 6 \mathrm{~cm}$, weighing around $1.7 \mathrm{~kg}$ each. Fen-Daqu is fermented and matured in stacked layers of blocks. Three matured Daqu blocks (having been stored for 6 months of maturation) were randomly selected from upper, middle and lower layers in order to obtain an adequate representation. Before performing microbiological analysis, each Daqu block was separated into two parts, namely its outer grayishcoloured surface layer of $1 \mathrm{~cm}$ thick, and the remaining brownishcoloured inner part. Both inner and outer parts were weighed before being ground to powder in an alcohol-disinfected grinder (Krups 75, model F203); the powder was kept in plastic jars at $4{ }^{\circ} \mathrm{C}$ during the experimental work.

\subsection{Microbiological analysis}

Samples of Daqu powder (10 g each) were transferred to stomacher bags and homogenized with $90 \mathrm{ml}$ sterile PPS (Peptone Physiological Salt) solution containing $(\mathrm{g} / \mathrm{L})$ peptone (Oxoid LP0034) 1, and $\mathrm{NaCl} \mathrm{8.5,} \mathrm{in} \mathrm{a} \mathrm{Stomacher} \mathrm{Lab-blender} \mathrm{400,} \mathrm{twice}$ $1 \mathrm{~min}$ at high speed. Appropriate serial dilutions were prepared using the same diluent. Unless otherwise indicated, $1 \mathrm{ml}$ portions of the diluted suspension were mixed with molten $\left(45^{\circ} \mathrm{C}\right)$ medium and poured in duplicate counting plates of the media described below.

Total aerobic and anaerobic bacteria were enumerated on Plate Count Agar (PCA; Oxoid CM035) and Reinforced Clostridial Agar (RCA; Oxoid CM0151), respectively. Plates were incubated at 30 and $55{ }^{\circ} \mathrm{C}$ for $1-2$ days.

For the enumeration of bacterial spores, the homogenized sample suspension was heated at $80^{\circ} \mathrm{C}$ for $5 \mathrm{~min}$. Serial dilutions were prepared from this heated suspension and mixed with PCA to which an additional top layer of $1.5 \%$ bacteriological agar (Oxoid, LP0011) was added to prevent spreading of colonies. Plates were incubated at both 30 and $55^{\circ} \mathrm{C}$ for 2 days.

Lactic acid bacteria (LAB) were enumerated on MRSA (Oxoid CM0361) with $0.1 \%(\mathrm{w} / \mathrm{v})$ natamycin (Delvocid, DSM, Delft, The Netherlands) to prevent yeast growth. Plates were incubated at $30{ }^{\circ} \mathrm{C}$ for $72 \mathrm{~h}$. To confirm the presence of presumed LAB, Gram 
staining and catalase reactions were carried out. The results were corrected, based on counting of Gram-positive and catalase negative organisms.

Enterobacteriaceae were counted with Violet Red Bile Glucose Agar (VRBGA; Oxoid CM0485). The medium was boiled twice before use. Plates were incubated at $37{ }^{\circ} \mathrm{C}$ for $24 \mathrm{~h}$. To confirm the presence of Enterobacteriaceae, oxidase - and glucose fermentation tests on presumptive colonies were carried out. The results were corrected based on the counting of oxidase negative, but glucose fermenting colonies.

Yeasts and moulds were enumerated on three different media, namely Malt Extract Agar (MEA; Oxoid CM0059), Dichloran-Glycerol Agar (DG18; Oxoid CM0097) and Rose Bengal Chloramphenicol Agar (RBCA; Oxoid CM0549), to which $100 \mathrm{mg} / \mathrm{L}$ chloramphenicol (Oxoid, SR0078E) was added. The diluted suspension $(0.1 \mathrm{ml})$ was added to make spread plates which were incubated at $25^{\circ} \mathrm{C}$ for $2-4$ days.

All enumerations of bacteria were carried out under both aerobic and anaerobic incubation conditions. Anaerobic growth conditions were achieved by flushing gas jars with a mixture of $80 \%$ nitrogen, $10 \%$ carbon dioxide, and $10 \%$ hydrogen. All counts were made in duplicate for each of the duplicated samples and the results were reported as the means $\pm \operatorname{SD}(n=4)$. From plates with 20-300 colonies, the square root of the total number of colonies were randomly selected as isolates.

\subsection{DNA extraction and PCR amplification}

Genomic DNA of bacteria was extracted by a Bacteria Genomic DNA Purification Kit (Tiangen, Beijing, China), according to the manufacturer's instructions. The 16S rDNA gene was amplified using forward primer 5'-AACGCGAAGAACCTTAC-3' and reverse primer 5'-CGGTGTGTACAAGACCC-3' (Niemann et al., 1997). Amplifications were performed in the thermocycler GeneAmp PCR system 9700 (Applied Biosystems, USA) with an annealing temperature of $56{ }^{\circ} \mathrm{C}$ and using reagents and Taq DNA polymerase from Fermentas. The PCR products were analyzed by electrophoresis and stored at $-20{ }^{\circ} \mathrm{C}$ for further sequencing analysis.

Genomic DNA of fungi was extracted by a Yeast Genomic DNA Purification Kit (Tiangen, Beijing, China), according to the manufacturer's instructions. The 26S rDNA and ITS regions were amplified by different primer sets. For yeast strains, forward primer NL1 (5'-TGCTGGAGCCATGGATC- $\left.3^{\prime}\right)$ and reverse primer RLR3R (5'GGTCCGTGTTTCAAGAC- $3^{\prime}$ ) were used for amplification of the D1/ D2 domain of the 26S rDNA gene; forward primer ITS1 (5'TCCGTAGGTGAACCTGCGG-3') and reverse primer ITS4 (5'TCCTCCGCTTATTGATATGC- $3^{\prime}$ ) were used for amplification of the ITS 1 and ITS2 regions (Okoli et al., 2007). For moulds, forward primer V9G ( $5^{\prime}$-TTACGTCCCTGCCCTTTGTA-3') and reverse primer LS266 (5'-GCATTCCCAAACAACTCGACTC-3') were used for amplification of ITS1-5.8S-ITS2 (Zhang et al., 2011c). Amplifications were performed with an annealing temperature of $52{ }^{\circ} \mathrm{C}$. The PCR products were analyzed as described before.

\subsection{Sequencing and strain identification}

The PCR products were purified using GFX columns (Amersham Pharmacia Biotech Inc., Roosendaal, The Netherlands). The bacterial and fungal rDNA was sequenced using the BigDye terminator cycle sequencing kit (Applied Biosystems) and analyzed on an ABI Prism 3700 sequencer (Applied Biosystems, Foster City, CA). The sequences were compared with those present in the GeneBank/ NCBI database using the BLAST 2.0 program (Altschul et al., 1990). Sequences were assembled and edited with Seqman II software (DNAStar Inc., Madison, Wis.) and aligned with Megalign (DNAStar Inc., Madison, Wis).

\subsection{DNA extraction and PCR-DGGE analysis}

DNA from Fen-Daqu samples was extracted according to Wang et al. (2008b) and diluted to $1-50 \mathrm{ng} / \mu \mathrm{L}$. Two sets of universal primers were tested for the amplification of fragments of the $16 \mathrm{~S}$ rRNA and 26S rRNA genes, respectively. The V6-V8 region of the 16S rRNA gene was amplified using the primers EUB968GC-for and EUBL1401-rev (500 bp) (Nubel et al., 1996). The D1 region of the $26 \mathrm{~S}$ rRNA gene was amplified using the primers NL1GC-for and LS2-rev (250 bp) (Flórez and Mayo, 2006). All PCR reactions were carried out on a AG 223B1 Thermoblock (Eppendorf, USA). Amplifications were performed as in Section 2.3. The sizes and quantities of the PCR products were determined using 1.5\% agarose gel electrophoresis. The amplification products obtained as described above were subjected to DGGE analysis using the Dcode Universal Mutation Detection system (BioRad Laboratories, Richmond, CA, USA) on $20 \mathrm{~cm} \times 16 \mathrm{~cm} \times 1 \mathrm{~mm}$ gels. Electrophoresis was performed at $60{ }^{\circ} \mathrm{C}$ in $0.5 \times$ TAE buffer $(20 \mathrm{mM}$ Tris-acetate, $2 \mathrm{mM}$ EDTA; pH 8.0) using 8\% polyacrylamide gels containing $30-60 \%$ urea-formamide linear denaturing gradient (100\% corresponded to $7 \mathrm{M}$ urea and $40 \% \mathrm{v} / \mathrm{v}$ formamide) increasing in the direction of electrophoresis for $16 \mathrm{~h}$ at $85 \mathrm{~V}$. Following electrophoresis, the gels were stained by $\mathrm{AgNO}_{3}$ solution as follows. The gel was fixed and shaken gently in Cairn's fixation solution $(200 \mathrm{ml} 96 \%$ ethanol; $10 \mathrm{ml}$ acetic acid; $40 \mathrm{ml}$ demi-water) for $3 \mathrm{~min}$. The gel was transferred to a freshly made $2 \mathrm{~g} / \mathrm{l} \mathrm{AgNO}_{3}$ staining solution and shaken gently for $10 \mathrm{~min}$, followed by a brief rinse in water. The stained gel was developed in a freshly made developing solution (10 $\mathrm{mg} \mathrm{NaBH}_{4} ; 250 \mathrm{ml} \mathrm{1.5 \%} \mathrm{NaOH}$ solution; $750 \mu$ l formaldehyde) until the desired exposure was achieved. The gel was scanned with "Quantity One" software using a calibrated imaging densitometer GS-710 (BioRad, CA, USA). The identity of the microorganisms was revealed by sequencing selected bands from the DGGE profiles. Small fragments of selected DGGE bands were punched out from the gels, put in sterile water and boiled for $30 \mathrm{~min}$ to release DNA. The gel solutions were cooled and stored overnight. The obtained supernatant was used directly for re-amplification of the PCR products with primers described above without GC clamp.

\subsection{Statistics}

Statistical analysis was carried out using IBM-SPSS V19.0 (IBM ${ }^{\circledR}$ SPSS ${ }^{\circledR}$ Statistics; NY, U.S.A). A one-way ANOVA with Duncan's test was used to determine the significance of different microbial enumeration data.

\section{Results}

\subsection{Enumeration of representative bacteria and fungi on selective media}

The population levels of bacteria and fungi that were present in the inner and outer portions of the Fen-Daqu starter are summarized in Table 1. The total viable numbers of mesophilic and thermophilic bacteria in the inner and outer parts were not significantly different; whereas the numbers of bacterial spores were significantly higher in the inner part. The numbers of mesophilic bacteria, including total viable cells, LAB and Enterobacteriaceae, were similar when grown under aerobic or anaerobic conditions. However, total numbers of thermophilic bacterial spores were about 1 Log CFU/g higher when grown aerobically, especially for the inner portion. The levels of LAB and Enterobacteriaceae were similar in both inner and outer portions of Daqu. The total counts of yeasts and moulds in inner Daqu were about $1 \mathrm{Log}$ CFU/g lower than in outer Daqu. No statistically significant differences were 
Table 1

Microbiota of inner and outer parts of Fen-Daqu presented as Log CFU g ${ }^{-1}$.

\begin{tabular}{|c|c|c|c|c|}
\hline \multirow{2}{*}{$\frac{\text { Log CFU g }^{-1}}{\text { Microbial groups }}$} & \multicolumn{2}{|l|}{ Aerobic counts } & \multicolumn{2}{|c|}{ Anaerobic counts } \\
\hline & Inner & Outer & Inner & Outer \\
\hline Mesophilic bacteria & $7.5 \pm 0.4^{\mathrm{def}}$ & $7.5 \pm 0.6^{\text {def }}$ & $7.4 \pm 0.2^{\text {cdef }}$ & $7.7 \pm 0.2^{\text {ef }}$ \\
\hline $\begin{array}{l}\text { Mesophilic bacterial } \\
\text { spores }\end{array}$ & $7.1 \pm 0.6^{\text {bcdef }}$ & $6.6 \pm 0.2^{\mathrm{bcd}}$ & $7.7 \pm 0.3^{\mathrm{ef}}$ & $6.8 \pm 0.4^{\text {bcdef }}$ \\
\hline $\begin{array}{l}\text { Thermophilic } \\
\text { bacteria }\end{array}$ & $7.4 \pm 0.1^{\text {cdef }}$ & $6.9 \pm 0.4^{\text {bcdef }}$ & $7.5 \pm 0.2^{\text {cdef }}$ & $6.7 \pm 0.5^{\mathrm{bcde}}$ \\
\hline $\begin{array}{l}\text { Thermophilic } \\
\text { bacterial spores }\end{array}$ & $7.8 \pm 0.3^{f}$ & $6.7 \pm 0.3^{\text {bcde }}$ & $7.2 \pm 0.2^{\text {bcdef }}$ & $6.4 \pm 0.5^{b c}$ \\
\hline Lactic acid bacteria & $4.0 \pm 0.4^{\mathrm{a}}$ & $4.9 \pm 0.3^{\mathrm{a}}$ & $4.0 \pm 0.3^{\mathrm{a}}$ & $4.8 \pm 0.2^{\mathrm{a}}$ \\
\hline Enterobacteriaceae & $4.0 \pm 0.6^{\mathrm{a}}$ & $4.8 \pm 0.8^{\mathrm{a}}$ & $4.0 \pm 1.2^{\mathrm{a}}$ & $4.8 \pm 0.7^{\mathrm{a}}$ \\
\hline Fungi on MEA $25^{\circ} \mathrm{C}$ & $6.2 \pm 0.7^{b}$ & $7.1 \pm 0.6^{\text {bcdef }}$ & & \\
\hline Fungi on MEA $37^{\circ} \mathrm{C}$ & $6.7 \pm 1.2^{\mathrm{bcde}}$ & $6.9 \pm 1.6^{\text {bcdef }}$ & & \\
\hline Fungi on DG18 $25^{\circ} \mathrm{C}$ & $6.3 \pm 0.5^{\mathrm{bcd}}$ & $7.1 \pm 0.3^{\text {bcdef }}$ & & \\
\hline Fungi on DG18 $37^{\circ} \mathrm{C}$ & $6.6 \pm 0.7^{\mathrm{bcd}}$ & $7.1 \pm 1.2^{\text {bcdef }}$ & & \\
\hline Fungi on RBCA $25^{\circ} \mathrm{C}$ & $6.7 \pm 0.5^{\mathrm{bcde}}$ & $7.7 \pm 0.6^{\mathrm{ef}}$ & & \\
\hline Fungi on RBCA $37^{\circ} \mathrm{C}$ & $6.7 \pm 0.5^{\text {bcde }}$ & $7.6 \pm 0.4^{\mathrm{def}}$ & & \\
\hline
\end{tabular}

Values represent means \pm SD $(n=4)$. Means with different superscripts are significantly different (One-Way ANOVA; $P<0.05$ ).

found for fungal counts when grown at $25^{\circ} \mathrm{C}$ or $37^{\circ} \mathrm{C}$. We noticed that isolation using RBCA resulted in higher number of countable colonies if compared to the other two media used, viz. MEA and DG18. Bacteria were generally numerically dominant microorganisms in Fen-Daqu, followed by yeasts and moulds. The numbers of fungal colony forming units were more than $2 \mathrm{Log}$ CFU/g higher than those of LAB and Enterobacteriaceae.

\subsection{Bacterial diversity based on identification of $16 S$ rDNA}

A total of 109 bacterial strains were randomly selected and identified by sequencing the $16 \mathrm{~S}$ rDNA. Thirteen species were encountered in Fen-Daqu. The results are presented in Table 2. Bacillus spp. were predominant in Fen-Daqu. Particularly, Bacillus licheniformis and Bacillus subtilis together represented about $57 \%$ of the bacteria isolated from inner and outer portions of Fen-Daqu. In addition, Brevibacterium sp., LAB, i.e. Enterococcus faecalis, Lactobacillus plantarum and Pediococcus pentosaceus, represented 4, 17, 6, and $6 \%$ of the total number of isolates, respectively. Other bacteria such as Salmonella enterica and Escherichia coli were also encountered in outer Daqu.

\subsection{Fungal diversity based on identification of D1/D2 domain of 26S rDNA and ITS region}

A total of 81 fungal strains were randomly selected and identified by rDNA sequencing as shown in Table 3. Absidia corymbifera,

Table 2

Bacterial diversity in Fen-Daqu.

\begin{tabular}{lllll}
\hline Species identification & $\begin{array}{l}\text { Related } \\
\text { GenBank } \\
\text { sequence }\end{array}$ & $\begin{array}{l}\text { \% of bacterial } \\
\text { isolates } \\
(n=109)\end{array}$ & $\begin{array}{l}\text { Isolated } \\
\text { from }^{\mathrm{a}}\end{array}$ & Identity \\
\hline Bacillus cereus & EU111736 & 1 & $\mathrm{O}$ & $380 / 380(100 \%)$ \\
Bacillus licheniformis & AF399743 & 39 & $\mathrm{I} \& \mathrm{O}$ & $393 / 393(100 \%)$ \\
Bacillus pumilus & EU874880 & 1 & $\mathrm{I}$ & $387 / 392(98.7 \%)$ \\
Bacillus subtilis & FJ225312 & 18 & $\mathrm{I} \& \mathrm{O}$ & $392 / 392(100 \%)$ \\
Brevibacterium sp. & EU596384 & 4 & $\mathrm{O}$ & $396 / 396(100 \%)$ \\
Escherichia coli & EU026432 & 1 & $\mathrm{O}$ & $364 / 365(99.7 \%)$ \\
Enterococcus faecalis & AB507170 & 17 & $\mathrm{I} \& \mathrm{O}$ & $389 / 391(99.5 \%)$ \\
Lactobacillus plantarum & FJ749885 & 6 & $\mathrm{O}$ & $362 / 363(99.7 \%)$ \\
Leuconostoc citreum & FJ040203 & 1 & $\mathrm{O}$ & $364 / 366(99.5 \%)$ \\
Micrococcus luteus & FJ380953 & 1 & $\mathrm{O}$ & $381 / 382(99.7 \%)$ \\
Pediococcus pentosaceus & FM179609 & 6 & I \& O & $352 / 352(100 \%)$ \\
Pseudomonas aeruginosa & GQ180118 & 2 & $\mathrm{O}$ & $369 / 370(99.7 \%)$ \\
Salmonella enterica & FJ997268 & 3 & $\mathrm{O}$ & $343 / 343(100 \%)$ \\
\hline
\end{tabular}

$n=$ the total number of isolates.

a $\mathrm{I} / \mathrm{O}$ : isolated from Inner or Outer part of Fen-Daqu.
Aspergillus flavus, Rhizopus stolonifer and Saccharomycopsis fibuligera occurred throughout the inner and outer portions of Fen-Daqu. Others were found only in the outer portion, namely Mucor circinelloides, Penicillium commune, Rhizomucor variabilis var. regularior, Pichia kudriavzevii (formally known as Issatchenkia orientalis), Wickerhamomyces anomalus (formally known as Pichia anomalus) and Saccharomyces cerevisiae. One species, Rhizomucor pusillus (1\%), was isolated from the inner portion. The predominant isolates consisted of $S$. fibuligera (56\%), A. corymbifera (11\%), W. anomalus (8\%), P. kudriavzevii (6\%) and R. stolonifer (6\%).

\subsection{Analysis of bacterial and fungal populations using denaturing gradient gel electrophoresis (DGGE)}

DGGE analysis of the amplified 16S rDNA fragments obtained from the samples of the inner and outer portions of Fen-Daqu provided the fingerprint shown in Fig. 2. Up to twelve bands, representing 10 different species were detected in the polyacrylamide gel. Bacillus spp., Lactobacillus spp. and Weissella spp. were the dominant bacterial species. A higher bacterial diversity was found in the outer layers of Daqu when compared to the inner part, as evidenced by the presence of Staphylococcus saprophyticus, Lactobacillus sanfranciscensis and Bacillus megaterium in the outer layers. DGGE fingerprints of the amplified fungal 26S rDNA fragments with primers NL1GC and LS2 are shown in Fig. 3. The identified mycobiota in the Fen-Daqu was less complex than the bacterial biota. Only four fungal species were detected, namely $W$. anomalus, $S$. fibuligera, P. kudriavzevii and Debaryomyces hansenii. The fungal biota of inner and outer Daqu layers were largely similar.

\section{Discussion}

The bacteria of Fen-Daqu represent higher numbers than the yeasts and moulds. It should be realised however that since yeast cells are larger than bacterial ones, this doesn't imply that bacteria have a larger metabolic impact on the eco-physiology or biochemistry of Daqu. Studies on other types of Daqu, i.e. lightflavour and strong-flavour Daqu types (Leimena, 2008; Qiao et al., 2004; Zhang, 1999) also showed the presence of high numbers of bacteria. This high level (7-8 Log CFU/g) of especially thermophilic bacteria and spores in Daqu makes this starter different from other Asian traditional alcoholic fermentation starters such as Men (Dung et al., 2007; Thanh et al., 2008) and Ragi (Hesseltine et al., 1988) of which the bacterial loads of 2.6-6.2 Log CFU/g and 4.3-5.8 Log $\mathrm{CFU} / \mathrm{g}$, respectively, represented mainly lactic acid bacteria.

Combining the results of culture-dependent and -independent analyses, we found that the outer layers of Fen-Daqu have a broader microbial biodiversity and higher numbers of mesophilic microorganisms than the inner part, which contained less species and higher numbers of thermophilic microorganisms, mostly Bacillus spp. This observation is consistent with those of previous studies (Shi et al., 2009; Wang et al., 2008a, b).

This "microbiota stratification" within the blocks of Daqu may be explained by the changes of temperature that take place during the processing of Fen-Daqu (Zheng et al., 2011), as well as the characteristics of the solid-state fermentation of Daqu, which results in mass - and heat gradients causing relatively high temperatures in the centre (inner portion) of the blocks (data not shown).

Fen-Daqu is a representative of light-flavour Daqu. During its manufacture by solid-state fermentation, the maximum temperature in the centre of the Daqu blocks during fermentation does not exceed $50{ }^{\circ} \mathrm{C}$ (Kang, 1991). Most bacteria tolerate these temperatures and, therefore, a wide range of bacterial species was observed in this type of Daqu, particularly at the somewhat cooler outside. 
Table 3

Fungal diversity in Fen-Daqu.

\begin{tabular}{|c|c|c|c|c|c|}
\hline Group of fungi & Species identification & Related Genbank sequence & \%fungal population $(n=81)$ & Isolated from $^{a}$ & Identity \\
\hline \multirow[t]{7}{*}{ Filamentous fungi } & Absidia corymbifera & AB305110 & 11 & $\mathrm{I} / \mathrm{O}$ & $757 / 758(99.9 \%)$ \\
\hline & Aspergillus flavus & FJ878681 & 4 & $\mathrm{I} / \mathrm{O}$ & $651 / 655(99.4 \%)$ \\
\hline & Mucor circinelloides & DQ118990 & 1 & $\mathrm{O}$ & $638 / 638(100 \%)$ \\
\hline & Penicillium commune & AF236103 & 3 & 0 & $669 / 676(99.0 \%)$ \\
\hline & Rhizomucor pusillus & AB369914 & 1 & I & $605 / 606(99.8 \%)$ \\
\hline & Rhizomucor variabilis var. regularior & DQ119007 & 2 & $\mathrm{O}$ & $528 / 530(99.6 \%)$ \\
\hline & Rhizopus stolonifer & DQ273817 & 6 & $\mathrm{I} / \mathrm{O}$ & $242 / 244(99.2 \%)$ \\
\hline \multirow[t]{4}{*}{ Yeasts } & Pichia kudriavzevii & AY939808 & 6 & $\mathrm{O}$ & $547 / 547(100 \%)$ \\
\hline & Saccharomyces cerevisiae & EU798694 & 2 & 0 & $652 / 654(99.7 \%)$ \\
\hline & Saccharomycopsis fibuligera & FJ475057 & 56 & $\mathrm{I} / \mathrm{O}$ & $728 / 728(100 \%)$ \\
\hline & Wickerhamomyces anomalus & EF449518 & 8 & 0 & $558 / 558(100 \%)$ \\
\hline
\end{tabular}

$n=:$ the total number of isolates.

a $\mathrm{I} / \mathrm{O}$ : isolated from Inner or Outer part of Fen-Daqu.

B. subtilis and B. licheniformis were the dominant members from the inner portion. Bacterial DGGE patterns also revealed the presence of Weissella cibaria and Weissella confusa. Interestingly, the total viable counts in the inner part of Daqu were sometimes lower than those of bacterial spores present, which may have been caused by heat-activation of spores during the preparatory heat treatment at

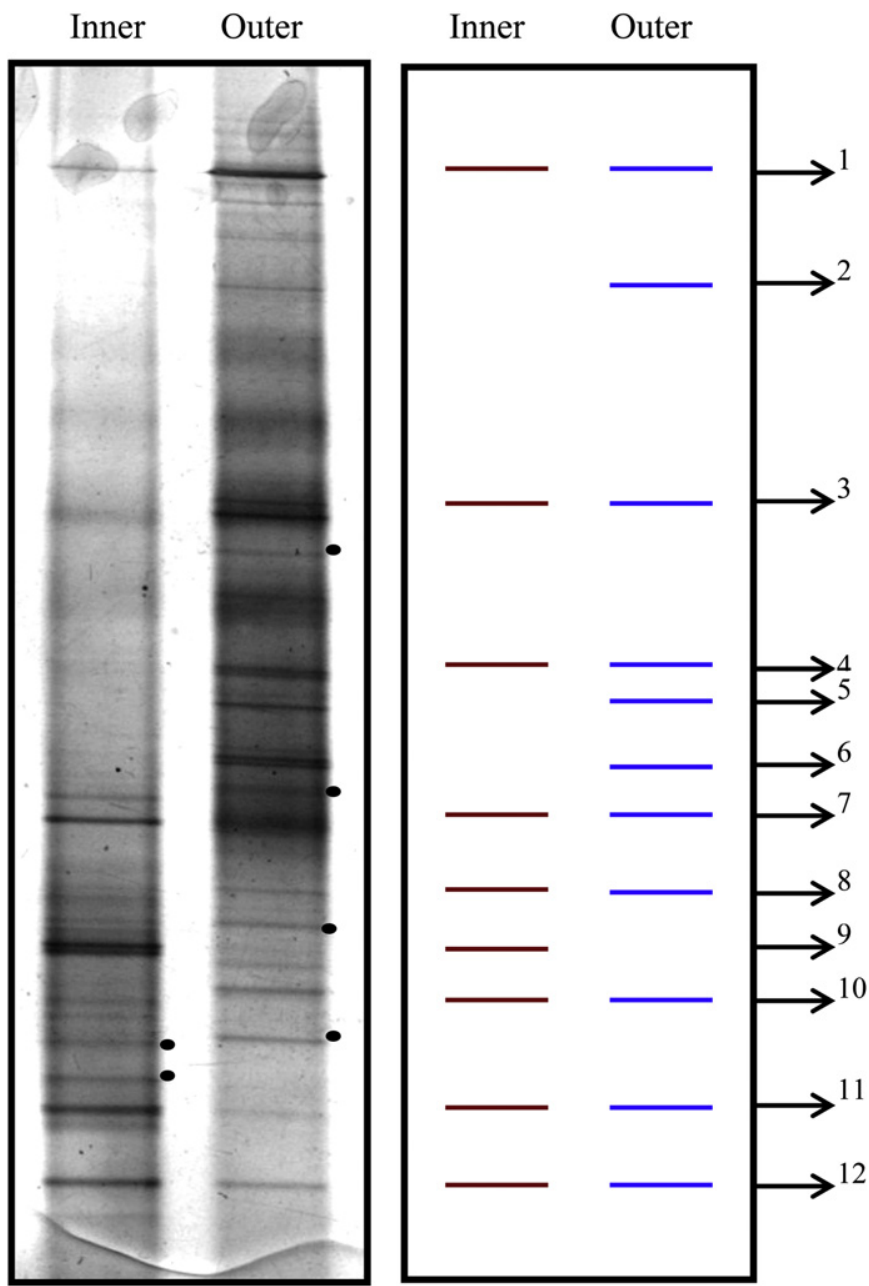

Fig. 2. DGGE profiles (30-60\% denaturant) representing bacterial $16 \mathrm{~S}$ rRNA gene fragments of Fen-Daqu samples. 1, Weissella cibaria; 2, Staphylococcus saprophyticus; 3 Enterobacter aerogenes; 4, Lactobacillus sanfranciscensis; 5, Lactobacillus lactis; 6, Bacillus megaterium; 7, Lactobacillus plantarum; 8, Weissella confusa; 9, Uncultured bacterium; 10, Bacillus licheniformis; 11, Weissella cibaria; 12, Weissella confusa. The dotted bands had also been excised but could not be identified since no amplicons were obtained.

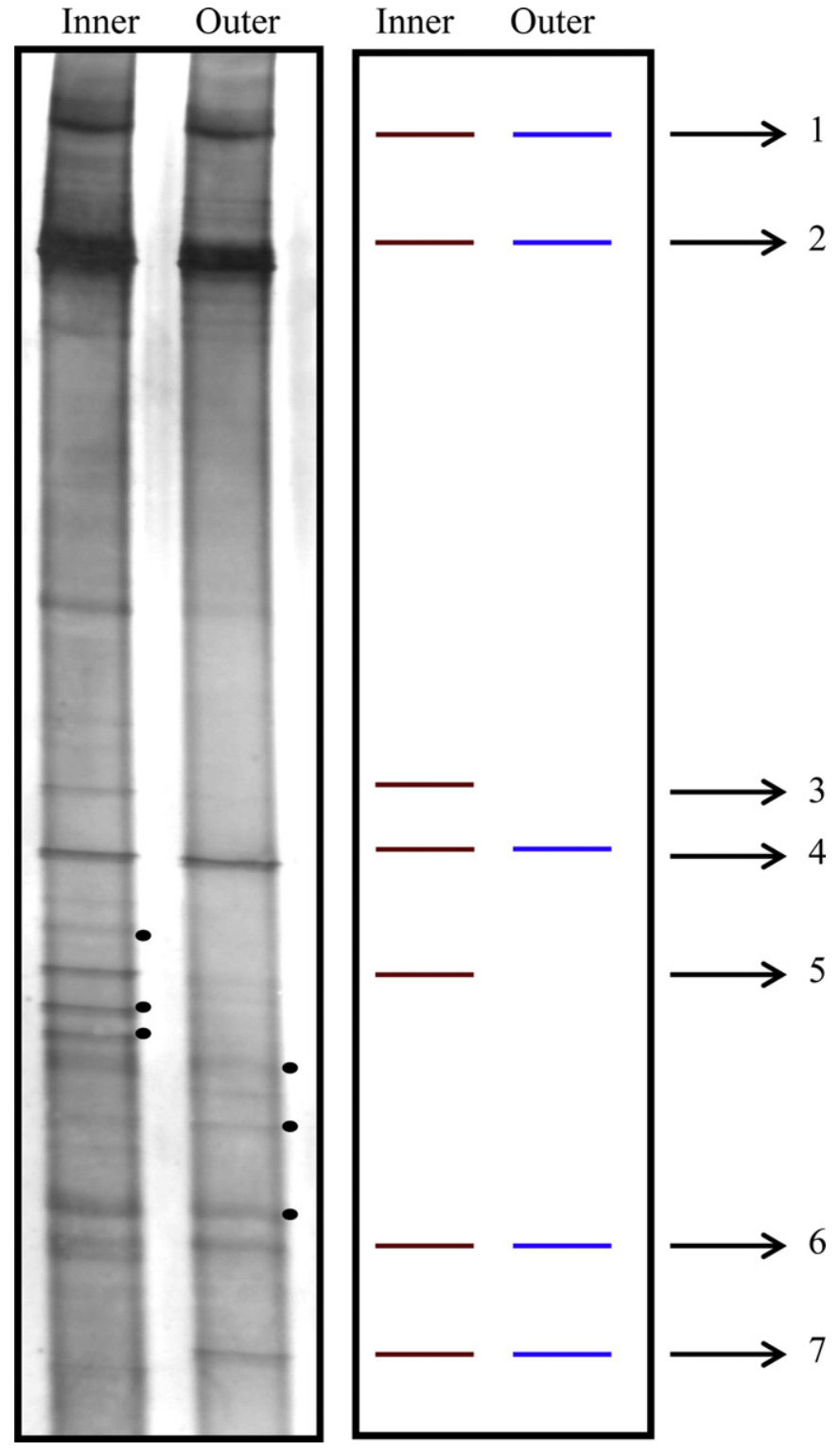

Fig. 3. DGGE profiles (30-65\% denaturant) representing $26 \mathrm{~S}$ rRNA gene fragments of Fen-Daqu samples. 1, Pichia kudriavzevii; 2, Saccharomycopsis fibuligera; 3, Wickerhamomyces anomalus; 4, Debaryomyces hansenii; 5, Pichia kudriavzevii; 6, Wickerhamomyces anomalus; 7, Pichia kudriavzevii. The dotted bands had also been excised but could not be identified since no amplicons were obtained. 
$80{ }^{\circ} \mathrm{C}$ for $5 \mathrm{~min}$ before plating (Morn et al., 1990). We note that spore-forming bacteria are the predominant microbiota of FenDaqu, especially in the inner part.

The analyses of microbial communities in Fen-Daqu were carried out by both culture-dependent and -independent approaches. The Bacillus spp. encountered in Fen-Daqu were B. licheniformis, B. subtilis, Bacillus pumilus, B. megaterium and Bacillus cereus. Of these, $B$. licheniformis was most prevalent with $39 \%$ strains identified and the species was detected by both approaches. B. subtilis was another dominant species, with $18 \%$ identified strains, but it could not be detected by DGGE. In comparison, the method used by Shi et al. (2009) encountered two Bacillus spp. in Fen-Daqu namely B. licheniformis and Bacillus decisifrondis.

The functionality of the bacterial biota needs further investigation. B. subtilis, B. licheniformis and B. pumilus may facilitate the conversion of starch into fermentable carbohydrates due to their amylolytic activity, thus generating a suitable substrate for the second stage of liquor production, i.e. the alcoholic fermentation (Mukherjee et al., 2009; Wang et al., 2008a). In addition, Bacillus spp. produce nitrogenous flavour compounds such as diverse pyrazines (Li et al., 2011; Zhang et al., 2011c; Zheng et al., 2011) and we expect that these to contribute to Daqu flavour.

Several lactic acid bacteria viz., Ent. faecalis, Pc. pentosaceus, $L b$. plantarum, Lb, lactis, Leuc. citreum, $W$. cibaria and $W$. confusa were identified that commonly occur in fermenting matter (Nout, 2009). Their contribution to the flavour development of Fen-Daqu or the final fermented liquor, for example, due to the formation of organic acids and other flavour compounds (Huang et al., 1993; Li and Ren, 2005; Wee et al., 2008) requires further attention.

Other bacteria including E. coli, Ps. aeruginosa, Micrococcus luteus, and $S$. enterica occurred in low numbers. Although we did not study their effects on quality or safety of Daqu we suggest that, because of their low numbers, they are not essential for the fermentation process, and that they originate from external contamination sources, such as air, soil, hands, or insects. Their presence, however, is not expected to pose a safety problem, as after fermentation, the product will be distilled to obtain the final liquor. During the steam distillation the cells of bacteria and fungi will be killed. Moreover, the alcohol concentration of the crude distillate is approximately $70 \% \mathrm{v} / \mathrm{v}$, which is adequate to practically sterilize the liquor.

In this study we used three mycological media (MEA, DG18 and RBCA) (Boekhout and Robert, 2003) to increase the detection of diverse fungal biota. In Daqu analysis, RBCA was superior for yeasts and moulds enumeration, mainly because distinct individual colonies were obtained and spreading of mould colonies was inhibited due to the presence of rose bengal (Baggerman, 1981). DG18 proved most appropriate to distinguish between yeasts and moulds, although yeasts were occasionally overgrown by spreading fungi, such as Mucor spp.

In contrast with the distinct bacterial population, the yeast microbiota identified from Fen-Daqu is more similar to that described from other Asian traditional alcoholic starters (Hesseltine et al., 1988; Jeyaram et al., 2008; Saelim et al., 2008; Sujaya et al., 2004; Tsuyoshi et al., 2005). These studies revealed that S. fibuligera occurred commonly in these starters, and this species plays an important role during the initial stages of alcoholic fermentation. $S$. fibuligera typically grows prior to the main alcoholic fermentation and produces various enzymes, particularly glucoamylase and $\alpha$ amylase, which contribute to glucose accumulation (Brimer et al., 1998; Horváthová et al., 2004; Knox et al., 2004; Lemmel et al., 1980; Steverson et al., 1984). It was also found that glucoamylase produced by $S$. fibuligera can digest native starch (Chi et al., 2009), which improves the degradation of starch from the raw materials (i.e. barley and pea) of Daqu. S. cerevisiae usually dominates in alcoholic fermentations (Li et al., 2011; Nout, 2009; Urso et al., 2008 ) as it has the ability to grow under strictly anaerobic conditions. However, in the DGGE profiles, S. cerevisiae was not detected and using isolation only one strain of $S$. cerevisiae was obtained. This demonstrates that $S$. cerevisiae is not a dominant yeast species in Daqu. Recently, a study of Li et al. (2011) investigated the species that involved in-situ Fen-liquor fermentation. This result indicated that the major active yeast species during this fermentation process was $S$. cerevisiae. The dominance of $S$. cerevisiae in alcoholic fermentation might be due to its competitive growth in the presence of fermentable sugars and its ethanol tolerance. We expect that it could grow quickly and become dominant during the liquor fermentation stage, such as has been observed in various wine fermentations (Dung et al., 2006, 2007; Jeyaram et al., 2008; Nyanga et al., 2007; Sujaya et al., 2004). Or it might be the host yeast species recycled in the fermentation jars. Mohanty et al. (2009) investigated the effect of different environmental factors on the $S$. cerevisiae fermentation. They observed that the combination of higher temperatures and lower moisture contents decreased the fermentation efficiency and ethanol production. During the Daqu production process, the fermentation temperature reached as high as above $55^{\circ} \mathrm{C}$, with moisture contents decreasing to around $10 \%$ at the end of maturation. Such conditions could be expected to limit the growth and survival of $S$. cerevisiae. This may thus well explain the low numbers of $S$. cerevisiae in matured Daqu. Other yeasts, such as $P$. kudriavzevii and $W$. anomalus, were observed in Daqu as well by both detection approaches. These yeast species are common in cereal fermentations (e.g. men, hamei, wheat qu and zaopei) and in combination with LAB, have been associated with the production of flavour and ethanol (Dung et al., 2006; Jeyaram et al., 2008; Nout, 2009; Thanh et al., 2008; Xie et al., 2007; Zhang et al., 2007).

Six genera of moulds, viz., Absidia, Aspergillus, Mucor, Penicillium, Rhizomucor and Rhizopus were obtained by direct plating. The predominant moulds in Fen-Daqu were A. corymbifera and $R$. stolonifer (Mucoraceae), which are known to be strong amylase producers (Blandino et al., 2003; Hesseltine et al., 1988; Thanh et al., 2008). M. circinelloides, Rhizomucor variabilis var. regularior, $R$. pusillus and P. commune were also isolated. In other fermentations, these moulds were responsible for volatile production during fermentation, such as ethanol, 2-methyl-1-butanol and 3methyl-1-butanol (Sunesson et al., 1996, 1995; Wang et al., 2008a). In our analysis of Fen-Daqu, A. flavus was found as well. This species is known to produce aflatoxins (Degola et al., 2007) and, therefore, it may be prudent to check for the presence of mycotoxins in Daqu and derived products. Sometimes, the DGGE method using total DNA extracted from complex food products is unable to detect some fungal species, whereas these could be detected by culturing and identification by DNA sequencing. Cocolin et al. (2001) and Prakitchaiwattana et al. (2004) reported that individual species in a mixed population could be detected by DGGE when the concentrations were higher than $10^{4} \mathrm{CFU} / \mathrm{g}$, which may be the threshold level to detect species. Fen-Daqu is a kind of solid cake covered with mycelia of white moulds that mainly belong to the so-called zygomycetes. It seems that DNA of this group of fungi is more difficult to extract, even when pure cultures are used (Hrncirova et al., 2010). We assume that the absence of bands for this group of fungi in our DGGE gel is mainly caused either by (i) inadequate DNA extraction of filamentous fungi from the complex food matrix of Daqu, or (ii) by the presence of high concentrations of competing DNA, such as that from yeasts in FenDaqu.

Presently, the study of microbial diversity can be undertaken with culture-dependent and/or culture-independent analyses. Both approaches have their advantages and disadvantages. From our 
study, we conclude that the culture-dependent analysis of Daqu samples resulted in a different and more complex microbiota than did DGGE analysis. A clear advantage of culturing is that a collection of pure cultures is obtained that can be used for further experimentation. A number of species (B. licheniformis, $L b$. plantarum, $S$. fibuligera, $P$. kudriavzevii and $W$. anomalus) were detected using both approaches, that in total revealed 30 species, most of which were found by either the culture-dependent or cultureindependent technique. This shows that although PCR-DGGE analysis provides a broad picture of the different groups of microorganisms present in Daqu, including unculturable ones, a combined approach is preferred for the detection of dominant and minor species in order to better understand the complete microbial ecosystem present in such natural mixed fermentation starters.

Fen-Daqu is a representative of low-temperature Daqu. Although the manufacturing techniques have been modernized during recent years, the inconsistency and instability of Daqu is still a problem that hampers the standardization of Chinese liquor making. Our study provides qualitative and quantitative information on the microbial diversity present in Fen-Daqu. The knowledge of microbial composition and functionality will enable further upgrading of the Chinese traditional Daqu making processes, e.g. by selection of functionally important strains, and optimization of microbial composition and quality control.

\section{Acknowledgements}

We thank Judith Wolkers-Rooijackers and Ma Kai for technical assistance; Jos Houbraken and Bart Theelen for sequencing support and Shanxi Xinghuacun Fenjiu Group Company for Daqu sampling assistance and advice. This project was supported by the National Natural Science of China (No.31071592) and grant KNAW-China Joint Research Project 07CDP015 from the Royal Netherlands Academy of Arts and Sciences.

\section{References}

Altschul, S.F., Gish, W., Miller, W., Myers, E.W., Lipman, D.J., 1990. Basic local alignment search tool. Journal of Molecular Biology 215, 403-410.

Anonymous, 2008. Annual report of national Chinese liquor program committee Liquor Making 35, 118 (in Chinese).

Aquilanti, L., Santarelli, S., Silvestri, G., Osimani, A., Petruzzelli, A., Clementi, F., 2007. The microbial ecology of a typical italian salami during its natural fermentation. International Journal of Food Microbiology 120, 136-145.

Baggerman, W.I., 1981. A modified rose bengal medium for the enumeration of yeasts and moulds from foods. European Journal of Applied Microbiology and Biotechnology 12, 242-247.

Blandino, A., Al-Aseeri, M.E., Pandiella, S.S., Cantero, D., Webb, C., 2003. Cerealbased fermented foods and beverages. Food Research International 36 $527-543$.

Boekhout, T., Robert, V., 2003. Yeasts in Food: Beneficial and Detrimental Aspects. Behr's Verlag, Hamburg.

Brimer, L., Nout, M.J.R., Tuncel, G., 1998. $\beta$-glycosidase (amygdalase and linamarase) from Endomyces fibuliger (LU677): formation and crude enzyme properties. Applied Microbiology and Biotechnology 49, 182-188.

Camu, N., De Winter, T., Verbrugghe, K., Cleenwerck, I., Vandamme, P., Takrama, J.S., Vancanneyt, M., De Vuyst, L., 2007. Dynamics and biodiversity of populations of lactic acid bacteria and acetic acid bacteria involved in spontaneous heap fermentation of cocoa beans in Ghana. Applied and Environmental Microbiology 73, 1809-1824.

Chi, Z., Chi, Z., Liu, G., Wang, F., Ju, L., Zhang, T., 2009. Saccharomycopsis fibuligera and its applications in biotechnology. Biotechnology Advances 27, 423-431.

Cocolin, L., Manzano, M., Cantoni, C., Comi, G., 2001. Denaturing gradient gel electrophoresis analysis of the $16 \mathrm{~S}$ rRNA gene V1 region to monitor dynamic changes in the bacterial population during fermentation of Italian sausages. Applied and Environmental Microbiology 67, 5113-5121.

Degola, F., Berni, E., Dall' Asta, C., Spotti, E., Marchelli, R., Ferrero, I., Restivo, F.M., 2007. A multiplex RT-PCR approach to detect aflatoxigenic strains of Aspergillus flavus. Journal of Applied Microbiology 103, 409-417.

Dung, N.T.P., Rombouts, F.M., Nout, M.J.R., 2006. Functionality of selected strains of moulds and yeasts from Vietnamese rice wine starters. Food Microbiology 23, $331-340$.
Dung, N.T.P., Rombouts, F.M., Nout, M.J.R., 2007. Characteristics of some traditional Vietnamese starch-based rice wine fermentation starters (men). LWT - Food Science and Technology 40, 130-135.

Fan, W.-L., Xu, Y., Zhang, Y.-H., 2007. Characterization of pyrazines in some Chinese liquors and their approximate concentrations. Journal of Agricultural and Food Chemistry 55, 9956-9962.

Flórez, A.B., Mayo, B., 2006. PCR-DGGE as a tool for characterizing dominant microbial populations in the Spanish blue-veined Cabrales cheese. International Dairy Journal 16, 1205-1210.

Hesseltine, C.W., Rogers, R., Winarno, F.G., 1988. Microbiological studies on amylolytic oriental fermentation starters. Mycopathologia 101, 141-155.

Horváthová, V., Slajsová, K., Sturdík, E., 2004. Evaluation of the glucoamylase Glm from Saccharomycopsis fibuligera IFO 0111 in hydrolysing the corn starch. Biologia - Section Cellular and Molecular Biology 59, 361-365.

Hrncirova, K., Lengerova, M., Kocmanova, I., Racil, Z., Volfova, P., Palousova, D., Moulis, M., Weinbergerova, B., Winterova, J., Toskova, M., Pospisilova, S., Mayer, J., 2010. Rapid detection and identification of mucormycetes from culture and tissue samples by use of high-resolution melt analysis. Journal of Clinical Microbiology 48, 3392-3394.

Huang, B.-J., Xu, Y.-G., Yu, G.-T., Jiang, Q.-P., 1993. Influence of microbiota on the typical flavour of Site Daqu. Liquor-making Science and Technology 4, 24-26 (in Chinese).

Iacumin, L., Cecchini, F., Manzano, M., Osualdini, M., Boscolo, D., Orlic, S., Comi, G., 2009. Description of the microflora of sourdoughs by culture-dependent and culture-independent methods. Food Microbiology 26, 128-135.

Jeyaram, K., Singh, W.M., Capece, A., Romano, P., 2008. Molecular identification of yeast species associated with 'Hamei' - a traditional starter used for rice wine production in Manipur, India. International Journal of Food Microbiology 124, 115-125.

Kang, M.-G., 1991. Handbook of Liquor Industry. China Light Industry Press, Beijing (In Chinese)

Knox, A.M., du Preez, J.C., Kilian, S.G., 2004. Starch fermentation characteristics of Saccharomyces cerevisiae strains transformed with amylase genes from Lipomyces kononenkoae and Saccharomycopsis fibuligera. Enzyme and Microbial Technology 34, 453-460.

Leimena, M.M., 2008. Microbial ecology and functionality of traditional fermentation starter "Daqu" for liquor production. Laboratory of Food Microbiology, MSc-thesis, Wageningen University, Wageningen, pp. 1-74.

Lemmel, S.A., Heimsch, R.C., Korus, R.A., 1980. Kinetics of growth and amylase production of Saccharomycopsis fibuligera on potato processing wastewater. Applied and Environmental Microbiology 39, 387-393.

Li, X.-R., Ma, E.-B., Yan, L.-Z., Meng, H., Du, X.-W., Zhang, S.-W., Quan, Z.-X., 2011. Bacterial and fungal diversity in the traditional Chinese liquor fermentation process. International Journal of Food Microbiology 146, 31-37.

Li, Z.-S., Ren, R.-B., 2005. Changes of dominant groups of microorganisms during production of light-flavour Daqu. Liquor Making 32, 33-34 (in Chinese).

Mohanty, S.K., Behera, S., Swain, M.R., Ray, R.C., 2009. Bioethanol production from mahula (Madhuca latifolia L.) flowers by solid-state fermentation. Applied Energy 86, 640-644.

Morn, L., Row, M.T., Hagan, J.A., 1990. The effect of various heat activation treatments on fast, intermediate and slow germinating spores of Bacillus spp. Letters in Applied Microbiology 10, 43-46.

Mukherjee, A.K., Borah, M., Rai, S.K., 2009. To study the influence of different components of fermentable substrates on induction of extracellular $\alpha$-amylase synthesis by Bacillus subtilis DM-03 in solid-state fermentation and exploration of feasibility for inclusion of $\alpha$-amylase in laundry detergent formulations. Biochemical Engineering Journal 43, 149-156.

Niemann, S., Pühler, A., Tichy, H.V., Simon, R., Selbitschka, W., 1997. Evaluation of the resolving power of three different DNA fingerprinting methods to discriminate among isolates of a natural Rhizobium meliloti population. Journal of Applied Microbiology 82, 477-484.

Nout, M.J.R., 2009. Rich nutrition from the poorest - cereal fermentations in Africa and Asia. Food Microbiology 26, 685-692.

Nubel, U., Engelen, B., Felske, A., Snaidr, J., Wieshuber, A., Amann, R.I., Ludwig, W., Backhaus, H., 1996. Sequence heterogeneities of genes encoding 16S rRNAs in Paenibacillus polymyxa detected by temperature gradient gel electrophoresis. Journal of Bacteriology 178, 5636-5643.

Nyanga, L.K., Nout, M.J.R., Gadaga, T.H., Theelen, B., Boekhout, T., Zwietering, M.H., 2007. Yeasts and lactic acid bacteria microbiota from masau (Ziziphus mauritiana) fruits and their fermented fruit pulp in Zimbabwe. International Journal of Food Microbiology 120, 159-166.

Okoli, I., Oyeka, C.A., Kwon-Chung, KJ., Theelen, B., Robert, V., Groenewald, J.Z. McFadden, D.C., Casadevall, A., Boekhout, T., 2007. Cryptotrichosporon anacardii gen. nov., sp. nov., a new trichosporonoid capsulate basidiomycetous yeast from Nigeria that is able to form melanin on niger seed agar. FEMS Yeast Research 7, 339-350.

Papalexandratou, Z., Vrancken, G., De Bruyne, K., Vandamme, P., De Vuyst, L., 2011. Spontaneous organic cocoa bean box fermentations in Brazil are characterized by a restricted species diversity of lactic acid bacteria and acetic acid bacteria. Food Microbiology 28, 1326-1338.

Prakitchaiwattana, C.J., Fleet, G.H., Heard, G.M., 2004. Application and evaluation of denaturing gradient gel electrophoresis to analyse the yeast ecology of wine grapes. FEMS Yeast Research 4, 865-877.

Qiao, Z.-W., Zhang, W.-X., Zhang, L.-Y., Hu, C., Men, Y., Wang, Z.-Y., 2004. Selection of isolation media of microbes in the fermented grains of Luzhou-flavour liquors. Liquor-making Science and Technology 6 (126), 30-32. 
Saelim, K., Dissara, Y., H-Kittikun, A., 2008. Saccharification of cassava starch by Saccharomycopsis fibuligera YCY1 isolated from Loog-Pang (rice cake starter). Songklanakarin Journal of Science and Technology 30, 65-71.

Shen, C.-H., Zhang, L., Ying, H., Xu, D.-F., Shen, C.-P., 2005. Study on Daqu quality standards (V)-investigation on the setting of Daqu quality judgement standards system. Liquor-making Science and Technology 11, 19-24 (in Chinese).

Shen, Y.-F., 2001. Chinese Liquor Industry. China Light Industry Press, Beijing (In Chinese).

Shi, J.H., Xiao, Y.P., Li, X.R., Ma, E.B., Du, X.W., Quan, Z.X., 2009. Analyses of microbia consortia in the starter of Fen Liquor. Letters in Applied Microbiology 48, 478-485.

Steverson, E.M., Korus, R.A., Admassu, W., Heimsch, R.C., 1984. Kinetics of the amylase system of Saccharomycopsis fibuliger. Enzyme and Microbial Technology 6, 549-554.

Sujaya, I.N., Antara, N.S., Sone, T., Tamura, Y., Aryanta, W.R., Yokota, A., Asano, K. Tomita, F., 2004. Identification and characterization of yeasts in brem, a traditional Balinese rice wine. World Journal of Microbiology and Biotechnology 20,143-150.

Sunesson, A.L., Nilsson, C.A., Andersson, B., Blomquist, G., 1996. Volatile metabolites produced by two fungal species cultivated on building materials. Annals of Occupational Hygiene 40, 397-410.

Sunesson, A.L., Vaes, W.H.J., Nilsson, C.A., Blomquist, G., Andersson, B., Carlson, R., 1995. Identification of volatile metabolites from five fungal species cultivated on two media. Applied and Environmental Microbiology 61, 2911-2918.

Thanh, V.N., Mai, L.T., Tuan, D.A., 2008. Microbial diversity of traditional Vietnamese alcohol fermentation starters (banh men) as determined by PCR-mediated DGGE. International Journal of Food Microbiology 128, 268-273.

Tsuyoshi, N., Fudou, R., Yamanaka, S., Kozaki, M., Tamang, N., Thapa, S., Tamang, J.P., 2005 Identification of yeast strains isolated from marcha in Sikkim, a microbial starter for amylolytic fermentation. International Journal of Food Microbiology 99, 135-146.

Urso, R., Rantsiou, K., Dolci, P., Rolle, L., Comi, G., Cocolin, L., 2008. Yeast biodiversity and dynamics during sweet wine production as determined by molecular methods. FEMS Yeast Research 8, 1053-1062.

Wang, C.-L., Shi, D.-J., Gong, G.-L., 2008a. Microorganisms in Daqu: a starter culture of Chinese Maotai-flavour liquor. World Journal of Microbiology and Biotechnology 24, 2183-2190.
Wang, H.-Y., Zhang, X.-J., Zhao, L.-P., Xu, Y., 2008b. Analysis and comparison of the bacterial community in fermented grains during the fermentation for two different styles of Chinese liquor. Journal of Industrial Microbiology and Biotechnology 35, 603-609.

Wee, Y.-J., Reddy, L.V.A., Ryu, H.-W., 2008. Fermentative production of L(+)-lactic acid from starch hydrolyzate and corn steep liquor as inexpensive nutrients by batch culture of Enterococcus faecalis RKY1. Journal of Chemical Technology and Biotechnology 83, 1387-1393.

Wu, X.-H., Zheng, X.-W., Han, B.-Z., Vervoort, J., Nout, M.J.R., 2009. Characterization of Chinese liquor starter, "Daqu" by flavor type with1H NMR-based nontargeted analysis. Journal of Agricultural and Food Chemistry 57, 11354-11359.

Xie, G.-F., Li, W.-J., Lu, J., Cao, Y., Fang, H., Zou, H.-J., Hu, Z.-M., 2007. Isolation and identification of representative fungi from Shaoxing rice wine wheat Qu using a polyphasic approach of culture-based and molecular-based methods. Journal of Institute of Brewing 113, 272-279.

Xiong, Z.-S., 2005. Research on three flavor type liquor in China (3) Fen flavo liquor-Xinghuacun. Liquor-making Science and Technology 7, 17-21 (in Chinese)

Zhang, C., Ao, Z., Chui, W., Shen, C., Tao, W., Zhang, S., 2011a. Characterization of the aroma-active compounds in Daqu: a traditional Chinese liquor starter. European Food Research and Technology 234, 69-76.

Zhang, C., Ao, Z., Chui, W., Shen, C., Tao, W., Zhang, S., 2011b. Characterization of volatile compounds from Daqu-a traditional Chinese liquor fermentation starter. International Journal of Food Science and Technology 46, 1591-1599.

Zhang, L., 1999. The analysis of microbes biology in middle temperature. Journal of Sichuan Food and Fermentation 4, 21-23 (in Chinese).

Zhang, W.-X., Qiao, Z.-W., Tang, Y.-Q., Hu, C., Sun, Q., Morimura, S., Kida, K., 2007. Analysis of the fungal community in Zaopei during the production of Chinese Luzhou-flavour liquor. Journal of the Institute of Brewing 113, 21-27.

Zhang, X., Wu, Z.-F., Zhang, S.-C., Hu, C., Zhang, W.-X., 2011c. Phylogenetic analysis of $18 \mathrm{~S}$ rDNA sequence of mold from Luzhou-flavor Daqu. Chinese Journal of Applied and Environmental Biology 17, 334-337.

Zheng, X.-W., Tabrizi, M.R., Nout, M.J.R., Han, B.-Z., 2011. Daqu-a traditional Chinese liquor fermentation starter. Journal of the Institute of Brewing 117, 82-90. 